\title{
A AIDS personificada no jornal Correio de Notícias (PR), 1987 a 1992
}

\author{
AIDS personified in the newspaper Correio de Notícias (PR), 1987 to 1992 \\ Personificación del SIDA en el periódico Correio de Notícias (PR), 1987 a 1992
}

\author{
José Augusto Leandro ${ }^{1, a}$ \\ joseaugustoleandro@gmail.com | https://orcid.org/0000-0002-3408-4404 \\ Marcos Vinícius Barszcz ${ }^{2, b}$ \\ marcosviniciuspsicologo@yahoo.com.br | https://orcid.org/o000-0001-9577-0355 \\ ${ }^{1}$ Universidade Estadual de Ponta Grossa, Departamento de História e Programa de Pós-Graduação em Ciências \\ Sociais Aplicadas. Ponta Grossa, PR, Brasil. \\ 2 Faculdade Sant'Ana, Departamento de Psicologia. Ponta Grossa, PR, Brasil. \\ a Doutorado em História Cultural pela Universidade Federal de Santa Catarina. \\ b Mestrado em Ciências Sociais Aplicadas pela Universidade Estadual de Ponta Grossa.
}

\section{RESUMO}

$\mathrm{O}$ artigo analisa as representações sociais sobre sujeitos identificados com sorologia positiva para HIV e/ou adoecidos pela aids veiculadas pelo periódico Correio de Notícias entre os anos de 1987 e 1992. Buscou-se perceber como um veículo de comunicação com circulação expressiva no estado do Paraná construiu uma determinada imagem encarnada do soropositivo para o HIV, em um período em que a AIDS era comumente considerada um vaticínio de morte e no qual a imprensa correntemente utilizava-se do termo 'aidético'. A partir dos dados obtidos, fez-se análise de conteúdo das matérias jornalísticas, com suporte na teoria das Representações Sociais. Identificou-se uma pluralidade de categorias temáticas, sobressaindo-se um conjunto de representações cujo significado mais imediato reforçou a estigmatização da pessoa com HIV e/ ou adoecida pela AIDS a partir de sua associação com crime, delito e contravenção.

Palavras-chave: HIV; AIDS; Representações Sociais; Imprensa periódica; Estigma. 


\section{ABSTRACT}

The article analyzes the social representations of people with HIV and/or sick of AIDS that were published by the newspaper Correio de Notícias between 1987 and 1992. The main purpose of the analysis was to understand how a newspaper of significant circulation in the state of Paraná built a certain stereotypic image of people HIV-positive at a time when the disease was considered a death prediction. From the obtained data, a content analysis of the journalistic materials was made, with support from the theory of the Social Representations. The survey identified a plurality of thematic categories with a set of representations whose most immediate significance reinforced the stigmatization of the person with HIV and/or sick of AIDS with an association with crime and misdemeanor.

Keywords: HIV; AIDS; Social Representations; Printed newspaper; Stigma.

\section{RESUMEN}

El artículo analiza las representaciones sociales de personas con VIH y/o enfermo de SIDA vehiculadas por el periódico Correio de Notícias entre 1987 y 1992. El propósito principal del análisis fue comprender cómo un periódico de circulación expresiva en el estado de Paraná construyó una determinada imagen encarnada del VIH positivo, en un período en que la enfermedad se consideraba una predicción de muerte. A partir de los datos obtenidos, se realizó un análisis de contenido de los materiales periodísticos, con el apoyo de la teoría de las Representaciones Sociales. El análisis identificó una pluralidad de categorías temáticas con un conjunto de representaciones cuyo significado más inmediato reforzó la estigmatización de la persona con VIH y/o con manifestación de estar enfermo de SIDA con una asociación con el crimen, el delito y otros desórdenes.

Palabras clave: VIH; SIDA; Representaciones Sociales; Periódicos impresos; Estigma.

Este artigo compõe o dossiê Comunicação, Saúde e Crises Globais: parte 2.

Contribuição dos autores:

Concepção e desenho do estudo: José Augusto Leandro e Marcos Vinícius Barszcz.

Aquisição, análise ou interpretação dos dados: José Augusto Leandro e Marcos Vinícius Barszcz.

Redação do manuscrito: José Augusto Leandro e Marcos Vinícius Barszcz.

Revisão crítica do conteúdo intelectual: José Augusto Leandro e Marcos Vinícius Barszcz.

Declaração de conflito de interesses: não há.

Fontes de financiamento: não houve.

Considerações éticas: não há.

Agradecimentos/Contribuições adicionais: não há.

Histórico do artigo: submetido: 5 set. 2020 | aceito: 15 jan. 2021 | publicado: 22 mar. 2021.

Apresentação anterior: não há.

Licença CC BY-NC atribuição não comercial. Com essa licença é permitido acessar, baixar (download), copiar, imprimir, compartilhar, reutilizar e distribuir os artigos, desde que para uso não comercial e com a citação da fonte, conferindo os devidos créditos de autoria e menção à Reciis. Nesses casos, nenhuma permissão é necessária por parte dos autores ou dos editores. 


\section{INTRODUÇÃO}

Ao olhar de cientistas sociais e historiadores, fenômenos epidêmicos são momentos únicos em que é possível verificar como determinados sentidos se articulam num contexto específico. Quando da ocorrência de epidemias emergem, muitas vezes, representações que expressam amálgamas de significados nas quais estão presentes aspectos da ciência, da cultura, da política, e que denotam a complexidade da vida em sociedade diante do fenômeno da doença. Essas representações tornam-se particularmente significativas para o entendimento dos mecanismos de construção social de sentidos à época que se pretende investigar (NASCIMENTO; CARVALHO, 2004). Para Charles Rosenberg, "doenças epidêmicas têm sido onipresentes na história da humanidade e, portanto, tornam-se fundamentais na negociação de valores sociais, de atitudes e de identidades individuais" (1989, p. 13).

Como bem observaram Herzlich e Pierret, “desde sua irrupção, em 1981, a AIDS representou mais do que uma nova doença. Rapidamente, ela preocupou não só os atingidos ou ameaçados, mas o conjunto da sociedade" (2005, p. 72). Para os estudiosos franceses, a AIDS logo mobilizou não somente médicos e pesquisadores, mas também profissionais artistas e políticos, de modo que a moderna síndrome evidenciou encadeamentos entre o biológico, o político e o social. No Brasil, o fenômeno social da AIDS se desenlaçou em meio ao contexto de redemocratização do país, na transição da década de 1970 para a de 1980. O entrelaçamento de sentidos políticos, econômicos e sociais característicos desse período particular na história do país contribuiu para o delineamento das respostas políticas e da publicização da infecção (MARQUES, 2003).

Dentre os meios pelos quais um sentido é construído, reificado e veiculado em meio à população, a imprensa periódica adquire papel particularmente significativo. Com efeito, Marques (2003) contextualiza a imprensa como o veículo que trouxe a AIDS a público no Brasil, contada conforme os Estados Unidos da América a apresentaram em seus períodos iniciais, a saber, um discurso da esfera médica relatando um câncer que infectava homossexuais - o 'câncer gay'. Nesse mesmo entendimento, Nascimento (2005) destaca que desde 1981 até pelo menos 1984, em periódicos como o Jornal do Brasil, por exemplo, houve persistência na veiculação da doença associada a homossexuais masculinos.

Foi somente ao longo da década de 1990, quando dados epidemiológicos apontavam também para uma heterossexualização da epidemia, que emergiram representações midiáticas oficiais menos estigmatizantes sobre grupos sociais específicos atingidos pelo HIV. Conforme aponta Lissandra Ramos, apesar de o tema da morte continuar sendo explícito ou camufladamente apresentado nas diversas campanhas de prevenção no Brasil, “o imaginário sobre a AIDS” (p. 34, 2016) daquele período passou a ser construído baseado "no fato de que, por ser incurável a doença e não existir tratamento eficaz e consolidado, a solidariedade, apoio e prevenção [eram] os elementos chaves no enfrentamento da epidemia no país” (RAMOS, 2016, p. 34).

No âmbito deste artigo, o que mais nos interessa é verificar como um novo fenômeno epidêmico foi 'encarnado' a partir de uma linguagem jornalística que apontava e caracterizava quem era o doente de AIDS. Nesse sentido, parte-se das considerações de Susan Sontag (2007) sobre os sentidos atribuídos à infecção, caracterizada como uma linguagem carregada de metáforas - uma praga, uma peste gay, um inimigo invasor do organismo e da própria sociedade - e sobre o doente - um indivíduo depreciado e estigmatizado não só por possuir o vírus, mas por outras questões a ele associadas, uma vez apontado e identificado enquanto um ser infectado. Para Sontag, "toda sociedade, ao que parece, precisa identificar uma determinada doença como o próprio mal, uma doença que torne culpadas as suas 'vítimas”' (2007, p. 89). 
Para atingir o objetivo aqui proposto, buscamos capturar qual a percepção mais imediata da personificação do sujeito denominado 'aidético'i no periódico Correio de Notícias entre 1987 e 1992. A teoria das Representações Sociais, de Serge Moscovici (2012a; 2012b), foi utilizada como suporte interpretativo para compreender os sentidos atribuídos à pessoa com sorologia positiva para o HIV e/ou adoecida por alguma moléstia decorrente da AIDS no periódico investigado. Uma vez que tal teoria se situa na intersecção entre fenômenos psicológicos e sociais, caracteriza-se como um referencial que sustenta a análise social da personificação da moléstia.

Desse modo, o presente texto inicia pontuando alguns aspectos acerca da fonte pesquisada e a metodologia de análise, e aponta algumas questões teóricas relevantes para o entendimento do nosso objeto de estudo. A seguir, dá-se a apresentação dos resultados, evidenciando as categorias identificadas, já articuladas à discussão central da presente proposta, isto é, demonstrando as personificações do denominado 'aidético' nas matérias e notícias veiculadas pelo referido jornal. As categorias, apesar de possuírem diferenças entre si, formam um 'bloco coeso', como demonstraremos mais adiante.

\section{SOBRE A FONTE E O PERCURSO METODOLÓGICO}

Compreender elementos de sentido representados por meios de comunicação exige conhecer, de fato, a natureza da fonte que é tomada para análise. Considera-se, como observam Massarani e Rocha (2018), que parcela do imaginário social sobre o conhecimento científico é fundamentalmente construída a partir da mídia, de modo que as fontes jornalísticas de uma determinada época representam dados tanto de comunicação quanto de construção de uma dada realidade social.

O trabalho com fontes de pesquisa em jornais seguiu algumas das considerações de Pontes e Silva (2012), em que se encontra um delineamento para a análise de elementos intertextuais e infratextuais de tais veículos. Segundo os estudiosos, a seleção do material de análise decorre de critérios que envolvem a abrangência de sua cobertura, o período histórico, a editoria em que se insere, o gênero das matérias e a própria estrutura de sua apresentação (PONTES; SILVA, 2012).

Com efeito, em meados da década de 1980, Renée Zicman já chamava atenção para o fato de que

a Imprensa age sempre no campo político-ideológico e, portanto, toda pesquisa realizada
a partir de jornais e periódicos deve necessariamente traçar as principais características
dos órgãos de Imprensa consultados. Mesmo quando não se faz História da Imprensa
propriamente dita - mas antes o que chamamos História Através da Imprensa - está-se
sempre 'esbarrando' nela, pela necessidade de historicizar os jornais (ZICMAN, 1985, p. 90).

Assim, parte-se da premissa de que o Correio de Notícias, editado no Paraná, foi um impresso representativo da imprensa paranaense. Além disso, o jornal, também à sua maneira, refletiu aspectos da imprensa nacional e internacional no período analisado, uma vez que replicou notícias veiculadas por empresas de comunicação de outros estados e países. Ele surgiu no contexto de alguns ventos de redemocratização, em 1978, quando a imprensa periódica passou a ser menos controlada pelos censores do regime militar, tanto no aspecto da vigilância da moral e dos bons costumes (SETEMY, 2018), como no monitoramento de publicações sobre a cobertura política em geral. Em 1980, após dois meses sem circular, seu expediente posicionou-se da seguinte maneira quando retornou às bancas, em 11 de março:

\footnotetext{
i O termo 'aidético/a', corrente na década de 1980 e em boa parte da década de 1990, contribuiu para que o imaginário social da época não distinguisse a doença do doente e, por conseguinte, a síndrome das doenças por ela ocasionadas. Muitas vezes, a mídia referia-se aos soropositivos para o HIV e aos adoecidos pela AIDS como termos equivalentes. Ao longo da segunda metade da década de 1990, o termo 'aidético/a' foi caindo em desuso e hoje é considerado como ofensivo e estigmatizante. No Brasil, somente em 2014 foi sancionada, pela presidenta Dilma Rousseff, a Lei $\mathrm{n}^{0}$ 12.984, de 2 de junho de 2014, que criminaliza "condutas discriminatórias contra o portador de HIV e o doente de aids, em razão de sua condição de portador ou de doente” (BRASIL, 2014).
} 


\begin{abstract}
Este é o primeiro dia de uma nova fase do CORREIO DE NOTÍCIAS. [...]. Procura preservar aquilo que o antigo CORREIO tinha de melhor: a pegada da reportagem, a preocupação em oferecer a melhor cobertura jornalística dos fatos. [...]. Numa sociedade em que a comunicação sofreu restrições é natural a surpresa que pode causar um jornalismo que surge para apresentar os fatos em sua plenitude. [...]. Se pretendemos realmente a construção de uma sociedade democrática, é preciso saber respeitar seus princípios. Entre eles, o da liberdade de imprensa [...]. No CORREIO vamos respeitar a opinião do morador do Boqueirão e do Tatuquara como respeitamos a do morador de centro da cidade. Os presidentes de associações de bairros terão a oportunidade de falar sobre a cidade como fala o prefeito (EL-KHATIB, 1980).
\end{abstract}

Apesar de não ter sido possível identificar dados sobre o número de exemplares impressos em cada tiragem ao longo dos anos (o expediente do veículo não trazia tal informação), tratava-se de um jornal de alcance regional, sobretudo no estado do Paraná, e com ampla distribuição na capital, Curitiba. Em março de 1980, seu diretor era Faruk El-Khatib, e seu editor-chefe era Fábio Campana; em 1985, o diretor presidente era Celso F. Hilbert, e o redator chefe era Mussa José Assis. Em 1991, o diretor era Cícero Amaral Cattani, e o chefe de redação era Francisco Camargo. Neste último ano, e já desde meados da década de 1980, o jornal tinha sucursais em Umuarama, Paranaguá, Toledo, Pato Branco, Guarapuava, Cascavel, Londrina, Maringá, Campo Mourão, Foz do Iguaçu; e contava com representantes no Rio de Janeiro, em São Paulo, em Belo Horizonte e em Brasília. Em 1991, o periódico era dividido em dois cadernos (A e B), cada qual com cerca de oito ou nove folhas.

O Correio de Notícias era mais ligado aos acontecimentos da capital do Paraná, onde se situavam sua redação e tipografia; entretanto, não deixava de reverberar, tematicamente, os conteúdos e as características do jornalismo da grande mídia impressa do país daquele momento. Dessa feita, o veículo de comunicação operou como uma fonte de informações sobre a doença, divulgando a um amplo público leitor essas mesmas informações dentro dos limites do conhecimento da ciência de então, bem como refletiu medos e preconceitos arraigados na sociedade da época (MARQUES, 2003). Os primeiros casos de AIDS no Brasil foram oficialmente reconhecidos a partir de 1982. "Mais tarde, um estudo retrospectivo indicou uma ocorrência de Aids em São Paulo ainda em 1980, ano que passou a ser referido em todas as análises epidemiológicas sobre o HIV no Brasil como o marco inicial" (MARQUES, 2002, p. 50-51).

Para a realização da pesquisa, utilizou-se como recurso de acesso ao jornal a plataforma digital da Hemeroteca da Biblioteca Nacional (FUNDAÇÃO BIBLIOTECA NACIONAL, 2020), especificando a busca a partir de filtros por periódico (Correio de Notícias, Paraná); por período (1980-1989 e 1990-1999); e por palavra-chave ('aidético'). A busca retornou resultados entre os anos de 1987 e $1992^{\text {ii }}$.

Em análise da apresentação da AIDS pela mídia televisiva no Brasil - por meio do telejornal Fantástico -, Barata (2006) observou que a epidemia detinha as condições necessárias para atender aos interesses midiáticos. O gênero fait divers, caracterizado pela apresentação de assuntos desviantes e excêntricos, limítrofes entre a realidade e a ficção, neste caso específico, trazia ao público o conforto ante sua própria imagem ao mesmo tempo em que legava ao jornalista o suposto papel de mero contador de histórias, de uma história que tensionava a realidade ainda não vivenciada para o distanciamento do ficcional. Barthes, citado por Pontes e Silva, define fait divers como "notícias gerais inclassificáveis, inomináveis frente ao catálogo conhecido. Remete, principalmente, a prodígios, catástrofes e crimes, tendo relação com aspectos míticos e da cultura popular" (2012, p. 59).

É possível afirmar que a imprensa periódica da época, para o caso de notícias de jornais em que se descrevia um doente de AIDS, não raramente enquadrava as histórias no gênero fait divers. Como uma mercadoria, os jornais do período visavam chamar a atenção do público para o incompreensível, o misterioso e o potencialmente fatal, agindo, desse modo, para atrair mais leitores e incrementar a venda

ii Constam na Hemeroteca Digital da Biblioteca Nacional edições do Correio de Notícias para os seguintes anos: 1980 , 1984 , 1985 (até meados de julho), e de 1986 a 1992. 
de exemplares. Não raramente, notícias eram revestidas com apelo emocional, com objetivo de fixar a atenção do leitor. Nesse sentido, a construção social da AIDS forneceu plenos elementos para um enredo sensacionalista, com personagens à espera de seu papel e de seu rótulo. Barata (2006) observa que na narrativa da epidemia houve o entrelaçamento de alguns aspectos: na construção da vilania do próprio vírus desencadeador de doenças (e mesmo na possível vilania representada pelos então chamados 'grupos de risco') associou-se a figura heroica dos pesquisadores da ciência; e, também, na urdidura da trama da AIDS foram expostas determinadas vítimas no enredo, "entre eles os hemofílicos, as crianças e as mulheres, sobretudo as casadas" (BARATA, 2006, p. 128-129). Os papéis atribuídos a cada um deles desenrolavam-se em meio a um cenário em que se destacava a temeridade pelo desconhecido.

A presente perspectiva sobre o periódico analisado é a de que o jornal, enquanto fonte de análise, possibilita interpretações sobre a realidade social de onde e para a qual publica - ou, como observam Pontes e Silva, “[...] o jornalismo como construtor da realidade que reporta” (2012, p. 50). Para os autores, uma notícia publicada é produto de uma ampla gama de determinações, de caráter pessoal e subjetivo, organizacional e editorial, de atores externos ao próprio periódico e da cultura profissional em que se inserem.

Teoricamente, vale destacar que, para Moscovici (2012b), o modo de representar da maioria das pessoas liga-se inextricavelmente ao senso comum. Este "está continuamente sendo criado e recriado em nossas sociedades, especialmente onde o conhecimento científico e tecnológico está popularizado" (2012b, p. 95). Nesse sentido, a imprensa periódica da década de 1980 e início da década de 1990 apresentou representações que forneceram elementos à ancoragem e à objetivação da AIDS e do seu doente, transformando o nãofamiliar em algo familiar. Enquanto a ancoragem, para Moscovici, "é um processo que transforma algo estranho e perturbador, que nos intriga, em nosso sistema particular de categorias e o compara com um paradigma de uma categoria que nós pensamos ser apropriada" (2012b, p. 61), a objetivação - "um processo muito mais atuante que a ancoragem" (p. 71) - consiste em fornecer substância à representação, fazendo com que um conceito se apresente em forma de uma imagem.

No caso da AIDS, sua ancoragem mais imediata pela imprensa se deu identificando-a como uma manifestação que atingia um outro pretensamente distante, a partir do momento em que se rotulou a síndrome de 'peste gay'; e, como já demonstrado por alguns estudiosos, isso foi, inclusive, chancelado pela ciência. Esta contou com o aval de "epidemiologistas equivocados" (BASTOS, 2006, p. 29) que relacionaram a AIDS sobretudo como atrelada a homossexuais masculinos. Assim, vale reforçar que, no período a que nos referimos, possuir o vírus e ser doente de AIDS eram, muitas vezes, termos equivalentes. $\mathrm{E}$ a vulgarização do termo 'aidético' serviu também como objetivação nos termos do psicólogo romeno naturalizado francês: materializou uma abstração (a AIDS ancorada enquanto peste/câncer gay) em uma imagem, de modo que 'aidético' (sobretudo o homem gay) tornou-se a "qualidade icônica de uma ideia" (MOSCOVICI, 2012b, p. 71).

As reportagens sobre as quais nos debruçamos foram analisadas tomando-se como base a análise de conteúdo temática (BARDIN, 2011), que oferece um referencial sistemático para descrição, codificação e análise do conteúdo de mensagens e suas variáveis de produção e recepção. A partir da etapa pré-analítica de seleção das fontes, procedeu-se à codificação das representações identificadas. Da palavra-chave buscada - 'aidético'-, retornou um total de 125 notícias, distribuídas em 78 resultados compreendidos entre os anos 1987 e 1989, e 47 abrangidos entre os anos de 1990 e 1992.

Pela análise de conteúdo, identificou-se, nessas 125 notícias, que muitas delas não caracterizavam o sujeito 'aidético', sendo o núcleo de sentido relacionado a outros temas que não a personificação do doente. Dentre elas: dados epidemiológicos, discursos autorizados de cientistas, medicação, política de saúde, comentários gerais sobre a doença, questões referentes ao contágio, entre outras. No entanto, um 
grupo significativo de matérias pesquisadas trouxe descrições do doente. Tais caracterizações, um total de 58, podem ser lidas como representações da personificação da síndrome e, nesse sentido, apresentaram particular interesse na análise.

Com Moscovici (2012a; 2012b), a análise de tais representações - o 'aidético' no Correio de Notícias - se adensa, possibilitando discutir os sentidos de construção de uma dada realidade social. A teoria das representações sociais do psicólogo desponta como suporte teórico que possibilita compreender como o não-familiar acaba por se tornar familiar a um dado contexto, isto é, que tipo de processos se dão para tornar elementos desconhecidos ou distantes do público geral em conhecimento amplamente difundido e conhecido.

Com efeito, a proposta teórica das representações analisa ambas as dimensões, social e psicológica, do fenômeno de construção de sentidos nos veículos de comunicação. Se como enfatiza Moscovici (2012b), o universo reificado do qual a ciência faz parte fornece a matéria-prima fundamental para a construção das ideias e visões do senso comum em determinados grupos - um universo consensual em que se dá a fluidez do cotidiano -, é necessário concentrar o esforço analítico nas formas de comunicação social que possibilitam conceitos às ancoragens e personificações à objetivação.

Por fim, no que tange ao percurso teórico-metodológico, cabe destacar que, ao se buscar compreender especificamente como uma doença tornou-se ‘encarnada' num sujeito doente, o ‘aidético', também tivemos no horizonte da análise a questão do estigma/estigmatização como possibilidade de construção pelo discurso da fonte investigada. Para Goffman (1975), três circunstâncias atuam para a ocorrência do estigma: as ligadas ao corpo, derivadas das diversas deformidades físicas; as ligadas às falhas do caráter dos indivíduos, como a desonestidade, por exemplo; e as relativas ao pertencimento a uma religião, raça ou nação. Para o sociólogo, "um indivíduo que poderia ser facilmente recebido na relação social quotidiana possui um traço que se pode impor atenção e afastar aqueles que ele encontra, destruindo a possibilidade de atenção para outros atributos seus" (GOFFMAN, 1975, p. 14). Nesse sentido, nos perguntamos se as personificações apresentadas pela mídia investigada forneceram material para que se construísse, no imaginário do leitor da época, algum outro tipo de estigma além do produzido pela corriqueira associação ao 'aidético' com a sua possível aparência física de extrema magreza.

\section{RESULTADOS E DISCUSSÃO}

A análise das fontes possibilitou a sintetização de uma pluralidade de sentidos em categorias temáticas para além da personificação. Dentre elas, como já mencionamos: a AIDS e notícias referentes a discursos sobre decisões e exigências de caráter político; notícias com divulgação de dados da infecção, evidenciando os avanços na epidemia a nível de municípios de grande porte do Brasil e de outros países (HERZLICH; PIERRET, 2005); a AIDS na fala de sujeitos cientistas caracterizados como detentores de discurso autorizado, isto é, autoridades dotadas de credibilidade que forneciam informações e perspectivas sobre a doença (EPSTEIN, 1996); mobilizações sociais e reivindicações de doentes e familiares; notícias advindas de outros países - sobretudo dos EUA; entre outras. Tal amplitude de resultados corresponde à perspectiva defendida de que a AIDS articulou, de modo ímpar, sentidos entre a medicina, a mídia e o social (EPSTEIN, 1996; ROSENBERG; GOLDEN, 1997; NASCIMENTO, 2005; PARKER; AGGLETON, 2001; GALVÃO, 2000).

A primeira notícia contendo a palavra 'aidético', de 1987, foi uma reportagem que destacava o preconceito com o doente. Nessa edição, cabe destacar, a AIDS foi uma chamada de capa, em letras centralizadas, garrafais e em tamanho expressivo diante das demais manchetes. No interior do jornal, a reportagem não se dirigiu ao doente propriamente dito, mas aos profissionais de saúde, que viam o 'aidético' como um paciente difícil de se lidar, não tanto pelas questões de ordem física, mas sobretudo pelas questões de 
ordem emocional, uma vez que era um sujeito estigmatizado. O título da reportagem do Correio de Notícias deixou clara a abordagem da matéria: "Preconceito, o maior obstáculo na luta dos médicos contra a Aids" (PRECONCEITO..., 1987). O texto lembrava, inclusive, que, "por preconceito, desinformação ou medo não raros funcionários de hospitais e de serviços de saúde se [recusavam] a manter contatos com os aidéticos" (PRECONCEITO..., 1987).

As matérias do jornal que personificaram o 'aidético' de uma maneira mais descritiva somaram um total de 58. A partir dessas matérias, criamos 13 categorias (Tabela 1), sendo que três delas se destacaram, formando um bloco coeso. Tal bloco, se levarmos em consideração o ordenamento jurídico penal vigente à época (1987-1992), refere-se, fundamentalmente, a crimes e contravenções (SOUZA; JAPIASSÚ, 2015): 'o criminoso', 'o transmissor voluntário', 'o desordeiro'. Essas três categorias encontram-se no cerne da presente análise, constituindo, apesar de suas diferenças, um núcleo intrinsecamente articulado de sentido.

Em menor representatividade despontaram reportagens que classificamos com as seguintes personificações: o 'paciente', 'a celebridade', 'o sobrevivente', 'a criança e o adolescente', o 'cidadão/sujeito de direitos', o 'paciente zero', o 'padre', o 'militar', o 'juiz de futebol' e o 'personagem de novela'. A totalidade dos resultados pode ser observada na tabela que segue:

Tabela 1 - Quantificação de notícias por categorias de personificação do 'aidético'

\begin{tabular}{lc} 
Categoria & $\begin{array}{c}\text { Total de notícias } \\
\text { identificadas }\end{array}$ \\
O criminoso & 14 \\
O transmissor voluntário & 13 \\
O desordeiro & 9 \\
O paciente & 7 \\
A celebridade & 5 \\
A criança e o adolescente & 2 \\
O cidadão sujeito de direitos & 2 \\
O sobrevivente & 1 \\
O paciente zero & 1 \\
O militar & 1 \\
O juiz de futebol & 1 \\
O padre & 1 \\
O personagem de novela & 1 \\
Total & $\mathbf{5 8}$ \\
\hline
\end{tabular}

Fonte: elaboração dos autores.

Na categoria 'o criminoso', tem-se um núcleo de sentido em que a apresentação de um indivíduo com HIV ou com alguma doença decorrente da AIDS se dá enquanto agente de alguma ação tipificada como crime pelo Código Penal vigente à época, ação esta que poderia ser de natureza variada. Destacaram-se reportagens que acompanharam o caso de prisioneiros que fugiram do então denominado 'manicômio judiciário’ no Paraná em novembro de 1987, e o caso de presos que fugiram da cadeia pública de Ribeirão Preto em julho de 1988; mas também ações como o tráfico e o consumo de drogas, bem como assaltos e agressão física, surgiram como temas das matérias publicadas, fossem elas de casos ocorridos no país ou no exterior.

Vale registrar que no caso do 'manicômio judiciário' do Paraná, situado próximo a Curitiba, este albergava, em partes de seu espaço, presos de outras cadeias do Estado que para ali eram transferidos a 
partir do diagnóstico positivo para o HIV. Uma reportagem do jornal sobre a instituição, datada de 11 de novembro de 1987, não se furtou a ilustrar a matéria com o chamativo título 'Exclusivo. Uma visita à ala B, o pavilhão dos aidéticos' (CAVALCANTI, 1987).

Também chamativo foi o título escolhido pelo Correio de Notícias para falar sobre um caso de suposto tráfico de drogas em Minas Gerais: 'Esperar a morte em casa, terapia brasileira' (1988). A matéria, do início de outubro de 1988, dava conta de que havia sido enquadrada como traficante de maconha - por terem sido encontrados 300 gramas da erva em sua casa - uma 'aidética' e modelo fotográfica de Belo Horizonte. A mulher negou insistentemente o crime: "disse que a maconha [pertencia] a seu marido, também aidético" (p. 6). Quando este compareceu à delegacia, confirmou o depoimento da esposa e afirmou que não era traficante e que continuaria fumando, "pois não [tinha] qualquer outro prazer" (p. 6). Disse que vivia "da venda de relógios" e que não tinha "qualquer perspectiva de vida, pois até os amigos se afastaram" (p. 6). A matéria publicada destacou que a mulher presa estava inconformada com a situação:

a modelo lembrou que esteve na França até cinco meses atrás, onde recebia um tratamento adequado para a doença. J. foi solto porque apresentava risco de contágio para os demais detentos. Ambos criticaram o tratamento dispensado aos aidéticos no País, frisando que 'a terapia no Brasil é a gente esperar a morte em casa' (p. 6).

A notícia do jornal findou registrando aos leitores que a modelo continuaria presa e que poderia ser solta "por decisão do juiz", que iria "receber o inquérito"(p. 6).

Algumas matérias do periódico foram eivadas de elementos narrativos que implicavam num julgamento moral do indivíduo pelo fato de ser soropositivo ou doente de AIDS. Foi o caso de um cabeleireiro preso por roubo de cheques. Este narrou à polícia que havia sido expulso de uma cidade do interior do Paraná, porque "comprovou-se que tinha Aids" (CABELEREIRO..., 1987, p. 5) e devido ao fato de que suas atitudes não eram ali consideradas "morais":

Segundo M., quando a família ficou sabendo de sua preferência sexual e de suas atividades, expulsou-o de casa. Veio então para Curitiba e quando tentou conseguir um emprego ou pelo menos algo para comer - já que estava com muita fome - dirigiu-se até o Convento do Cajuru. O roubo de cheques aconteceu por acaso. Quando foi pedir ajuda no Convento, viu-os em cima da mesa (eram cinco) e roubou-os - a oportunidade faz o ladrão (1987, p. 5).

O Correio de Notícias, no entanto, não se contentou em apenas noticiar o crime aos seus leitores. Registrou aspectos da intimidade do cabeleireiro, anotando que ele, uma vez em Manaus, havia se relacionado com um sujeito "cheio de perebas e manchas" (p. 5).

A categoria 'o transmissor voluntário' personificou sujeitos que transmitiram o vírus HIV por meio de relações sexuais ou de ataques com seringas contaminadas. Neste último caso, algumas matérias também versaram sobre tentativas não necessariamente consumadas. Tal categoria poderia situar-se no interior da categoria 'o criminoso', uma vez que, neste caso, a atitude do 'transmissor voluntário', sabedor do seu status sorológico, atentava contra a vida e a integridade física de outrem. No entanto, pela expressividade de número de matérias identificadas, optou-se por deixá-la numa categoria própria, à parte.

Como exemplo de 'transmissor voluntário' por relações sexuais, o Correio de Notícias, em reportagem de 29 de março de 1988, descreveu um "pedreiro 'aidético" acusado pela sogra de disseminar a doença. O pedreiro, segundo ela, afirmava: "Não vou afundar sozinho neste barco" (CAVALCANTI; GAERTNER; WILLICH, 1988, p. 6).

No caso das seringas contaminadas, as matérias publicadas traziam detalhes bem pormenorizados, como registrado no dia 3 de maio de 1988: 
Terminou com a morte do assaltante identificado apenas como R. a tentativa de assalto a agência do Banorte do município de Mossoró, a 275 quilômetros da Natal, no Rio Grande do Norte. Depois de oito horas de tensão, com a prisão no interior da agência de 13 reféns, um policial da Secretaria de Segurança Pública conseguiu atingir o assaltante com um tiro de revólver 38 pelas costas. O assaltante se dizia aidético e de posse de uma seringa com sangue ameaçou contaminar os reféns caso suas reivindicações não fossem atendidas. [...]. A tática da polícia foi ganhar tempo. [...] esperou que anoitecesse para poder invadir a agência. Tenso, nervoso, desconfiado, o assaltante - que não largava a seringa com sangue em nenhum instante - percebeu que os policiais estavam dispostos a invadir a agência e fez alguns disparos, contudo sem atingir nenhum dos reféns (ASSALTANTE..., 1988, p. 2).

Ainda sobre 'o transmissor voluntário', vale destacar uma reportagem de 8 de junho de 1989. Nela, o enredo da história narrada, sobre as ações de um 'aidético' 'toxicômano', foi contado pelo gênero fait divers, com grande destaque. A reportagem, sobre um fato ocorrido na cidade de Salvador, teve chamada na capa do Caderno B, com uma caixa de texto no canto superior esquerdo contendo os seguintes dizeres: 'Aidético pica quinze pessoas':

A Secretaria de Saúde da Bahia continua procurando as vítimas do aidético J. J. R. P., 35 anos, geólogo, que na noite da última segunda-feira picou várias pessoas no interior de um ônibus no bairro de Cabula, nesta capital, utilizando uma agulha que poderia estar contaminada. A. B. está preso na delegacia de tóxicos e entorpecentes e a população do bairro está em pânico, porque existe a suspeita de que pelo menos 15 pessoas foram feridas por ele. Ontem à tarde mais duas vítimas deram queixa contra o geólogo na polícia. Uma menina, L. de 10 anos, e um garoto R. de 11 anos. [...]. Ele é toxicômano e viciado em drogas injetáveis e a agulha que usou para picar os passageiros do ônibus que viajava [...] foi a mesma que momentos antes usara para se drogar, conforme confessou [...]. 'Eu entrei em alucinação. Pensava que cada uma das pessoas era um parente meu. Primeiro foi um rapaz. Depois uma moça e uma garota. Eu olhava para eles como se fossem meu pai, mãe, um irmão e sobrinha. Não sabia que estava com a agulha na mão' - confessou P.A., acrescentando que ainda estava sob efeito da cocaína que injetara na veia quando começou a picar as pessoas (AIDÉTICO..., 1989, p. 2).

Pode-se identificar reportagens de fatos advindos de contextos internacionais, em especial dos Estados Unidos e da Austrália - como nas manchetes 'Aidético louco ataca guarda e provoca greve na Austrália' (1990), e ‘Dentista transmite vírus da AIDS para paciente' (1990), notícia vinda dos EUA. Cabe destacar que em tais casos as notícias traziam poucas informações do contexto nacional, mas enfatizavam sobremaneira uma representação estigmatizante e, ao mesmo tempo, eram redigidas ligeiramente em tom chamativo e com apelo emocional ao interesse do consumo do leitor. A utilização de reportagens - nacionais e internacionais - que apelam para o caráter fait divers e o elemento de medo social comum parecem se repetir: um 'aidético' poderia, em qualquer lugar público e de modo súbito e intempestivo, infectar vítimas que não suspeitariam do risco iminente.

Pela categoria 'o desordeiro', englobam-se as pessoas com HIV e/ou com doenças decorrentes da AIDS que geraram, por vontade própria - ou apenas pela sua mera presença em algum ambiente específico -, tumulto e desordem social. No segundo caso (em menor quantidade), a perturbação não foi ocasionada por um comportamento peculiar ou ameaçador do 'aidético', mas apenas pelo conhecimento, por outrem, de seu status sorológico. As matérias normalmente referiam-se a profissionais de serviços públicos e privados - como hospitais, unidades psiquiátricas, creches e unidades prisionais que se recusavam a prestar seus serviços na presença do 'aidético'. A desordem não era ativamente provocada pelo 'portador' do vírus e/ou doente, mas uma reação direta ao seu diagnóstico.

Destacam-se, nesse conjunto temático, chamadas como: 'Chegada de paciente com AIDS gera greve em hospital Argentino', publicada em 2 de setembro de 1987; "AIDS, instituições não querem atender portador da doença", de 28 de dezembro de 1988; "EUA não dá visto de entrada a aidético e ameaça conferência", noticiada em 2 de junho de 1991; e casos como o de um juiz que fechou uma creche, em São Paulo, em razão da suspeita de que uma das crianças poderia ter o vírus HIV: 
O caso da creche G. F está provocando polêmica. O juiz de menores R. J. C., do Fórum distrital de Pinheiros, determinou que 42 menores, com idade entre três meses e 12 anos, fossem removidos para a unidade educacional da Febem, no começo da rodovia dos imigrantes. No ano passado o filho da dona da creche, S. R. L. O. morreu de tuberculose. Mas suspeitava-se que era aidético. O juiz ordenou o fechamento da creche por falta de condições (só existiam dois banheiros e quatro quartos) e a remoção dos menores para serem submetidos a testes. Catorze deles estão tuberculosos (JUIZ..., 1988, p. 6).

Noutras reportagens, trata-se de indivíduos que ativamente manifestaram comportamentos e atitudes desordeiras, algumas na forma de protesto, como o caso de um doente que invadiu um jantar oferecido pelo então presidente José Sarney ao presidente Carlos Menem, da Argentina, no palácio do Itamaraty, e espirrou um líquido vermelho - que alegou ser seu próprio sangue - bem próximo aos chefes de Estado. Nessa reportagem, a matéria publicada trouxe o seguinte chamativo título: 'Sarney quase vira aidético' (SCHNEIDER, 1989). Protestos nos EUA em favor de pessoas soropositivas também foram objeto do jornal. Dentre eles, uma notícia sobre um doente que, como último pedido antes da morte, teria solicitado a amigos que velassem seu corpo em frente ao comitê eleitoral de George Bush, com a mensagem " $\mathrm{E}$ aonde o senhor estava, sr. Presidente, enquanto a Aids se espalhava neste país?” (SCHULMANN, 1992, p. 4).

Ademais, é importante apontar alguns elementos referentes à estrutura de apresentação das fontes analisadas, no sentido de investigar a ênfase que o periódico deu a elas. As notícias sobre o 'aidético' com frequência ocupam o topo ou o centro das páginas em que foram expostas, com variações no tamanho da fonte - ora notadamente maior, ora de mesmo tamanho que as demais chamadas da página. Há também conteúdos que foram expostos em quadros mais reduzidos, nas porções inferiores ou laterais das páginas. Em síntese, as reportagens de maior destaque são aquelas com maior volume de conteúdo, ou aquelas mais potencialmente chocantes para a realidade do leitor. Já notícias de menor volume, mais distantes do público alvo do periódico - como fatos advindos da mídia internacional, e pequenos textos de comentaristas -, acabaram por obter uma exposição menos chamativa, em quadros ao final da página em tamanho reduzido.

Há, ainda, algumas reportagens que se destacam por sua chamada ao centro da página, em letras notadamente maiores que as demais - conferindo-lhes grande ênfase em suas respectivas edições. Dentre estas, pode-se citar as intituladas 'Exclusivo. Uma visita à ala B, o pavilhão dos aidéticos' (CAVALCANTI, 1987) e 'Sem informação oficial, saúde ignora preso com Aids' (1987). Cabe atentar novamente para os elementos que caracterizam o gênero fait divers, aqui evidenciados também em sua estrutura de diagramação no periódico.

Por fim, evidencia-se a prevalência de notícias expostas no Caderno Geral, o qual se caracteriza no periódico por apresentar reportagens informativas, sem caráter opinativo, cujas temáticas figuram entre política nacional e internacional, fatos inusitados e, por fim, crimes e seus processos judiciais. Em síntese, foi possível identificar que, sob uma pretensa neutralidade informativa, a construção do personagem 'aidético' pelo periódico Correio de Notícias (PR) se expressou tanto no conteúdo das notícias quanto em sua forma.

\section{CONCLUSÃO}

As três categorias que mais se destacaram em termos de personificação do soropositivo para HIV e/ou dos sujeitos com doenças decorrentes da AIDS aqui discutidas apontam para uma ênfase comum: pelas páginas da imprensa construiu-se um homem 'aidético' como um criminoso, um desordeiro, um desviante marginal e que poderia ser fonte de uma potencial disseminação consciente de um vírus a possíveis cidadãos inadvertidos. Tratava-se de um conjunto de sujeitos que reuniam em si uma síntese de elementos socialmente malogrados, de um grupo humano com o qual os leitores não se identificavam.

De fato, no período analisado, o enquadramento jornalístico operado pelo Correio de Notícias reforçou a percepção de que as doenças decorrentes da AIDS atingiam especificamente determinados tipos de 
indivíduos que constituíam um outro, pretensamente distante dos leitores do periódico. Nesse outro, ademais, uma possibilidade adicional de estigma era acoplada, para além da fraqueza e da magreza do corpo físico: o estigma moral pela falha de caráter, pois o 'aidético' surgia associado ao mundo do crime e das desordens comportamentais prescritas pelas normas jurídicas.

Observou-se que as matérias classificadas nas categorias 'o criminoso', 'o desordeiro' e 'o transmissor voluntário', em sua maioria trouxeram estampado o nome, o sobrenome, a idade e, em alguns casos, a profissão e até mesmo a foto dos sujeitos, quase que em sua totalidade homens. Uma única reportagem, dentre as analisadas, datada de 5 de outubro de 1988, a associação crime/AIDS é sobre uma mulher presa por suposto tráfico de maconha, com sua identidade e profissão igualmente expostas. Se, por um lado, os soropositivos para o HIV detinham direito à privacidade de seu diagnóstico, por outro lado, na medida que se tornavam 'aidéticos' criminosos, desordeiros ou contraventores da lei, suas identidades eram, muitas vezes, expostas. Apontamos ainda que a personificação da AIDS como representação sobretudo relacionada a homens corresponde a um momento em que a epidemia era entendida como comumente masculina.

As metáforas da AIDS como um inimigo e um símbolo da degenerescência da sociedade irromperam em representações que contribuíram para a exclusão e a estigmatização de inúmeros sujeitos. O gênero jornalístico fait divers acabou por construir e reificar representações sociais sobre o denominado 'aidético' que o objetivaram como um risco iminente ao convívio social. Não obstante, cabe lembrar que as discussões aqui apresentadas correspondem às opções teórico-metodológicas feitas pelos investigadores e vinculam-se ao recorte cronológico da pesquisa operada sobre um veículo de comunicação impresso específico.

Se a construção social das epidemias é repleta de conotações advindas de representações que articulam sentidos e significados provenientes de diferentes esferas das sociedades, a imprensa periódica deteve um papel relevante no caso da AIDS. O Correio de Notícias (PR), entre o final da década de 1980 e os primeiros anos da década de 1990, assim como muitos veículos de comunicação do período, contribuiu para a estigmatização de indivíduos vivendo com HIV e/ou com doenças decorrentes da AIDS, apresentando-os ao público, em determinados momentos, sob uma ótica narrativa que os culpabilizava pelo próprio status sorológico. E, mais do que isso: no processo de objetivação da personificação da doença no doente, o jornal contribuiu para que os seus leitores elaborassem imagens do denominado 'aidético' como um indivíduo perigoso a rondar a pretensa sociedade sã pela via do crime, da desordem e da contravenção.

\section{REFERÊNCIAS}

AIDÉTICO pica quinze pessoas. Correio de Notícias, Curitiba, 8 jun. 1989. Caderno B, p. 2.

AIDÉTICO louco ataca guarda e provoca greve na Austrália. Correio de Notícias, Curitiba, 25 de julho de 1990. Caderno A, p. 7.

AIDS, instituições não querem atender portador da doença. Correio de Notícias, Curitiba, 28 dez. 1988. Caderno A, p. 7.

ASSALTANTE invade banco usando seringa com sangue contaminado pelo vírus da AIDS como arma. Correio de Notícias, Curitiba, 3 maio 1988. Caderno Hora H, p. 2.

BARATA, Germana Fernandes. O "Fantástico" apresenta a Aids ao público (1982-1992). In: NASCIMENTO, Dilene Raimundo; CARVALHO, Diana Maul; MARQUES, Rita de Cássia (org.). Uma história brasileira das doenças. Rio de Janeiro: Mauad X, 2006. v. 2. p. 116-146.

BARDIN, Laurence. Análise de conteúdo. Tradução de Luís Antero Reto e Augusto Pinheiro. São Paulo: Edições 70, 2011.

BASTOS, Francisco Inácio. Aids na terceira década. Rio de Janeiro: Fiocruz, 2006. 
BRASIL. Lei no 12.984, de 2 de junho de 2014. Define o crime de discriminação dos portadores do vírus da imunodeficiência humana (HIV) e doentes de aids. Diário Oficial da União, Brasília, DF, 3 jun. 2014. Disponivel em: http://www.planalto.gov.br/ccivil_03/_Ato2011-2014/2014/Lei/L12984.htm. Acesso em: 31 ago. 2020.

CABELEIREIRO com Aids rouba para comer. Correio de Notícias, Curitiba, 14 jul. 1987. Caderno A, p. 6.

CAVALCANTI, Maurício. Exclusivo. Uma visita à ala B, o pavilhão dos aidéticos. Correio de Notícias, Curitiba, 11 nov. 1987. Caderno A, p. 7.

CAVALCANTI, Maurício; GAERTNER, Suman Geenen; WILLICH, Ricardo. Aidético é acusado pela sogra de disseminar a doença. Correio de Notícias, Curitiba, 29 mar. 1988. Caderno A, p. 6.

DENTISTA transmite vírus da Aids para paciente. Correio de Notícias, Curitiba, 28 jul. 1990. Caderno A, p. 1.

EL-KHATIB, Faruk. Um novo jornal. Correio de Notícias, Curitiba, 11 mar. 1980. Caderno A, p. 2.

ESPERAR a morte em casa, terapia brasileira. Correio de Notícias, Curitiba, 5 out. 1988. Caderno A, p. 6.

EPSTEIN, B. Impure Science: AIDS, Activism and the Politics of Knowledge. Oakland: University of California Press, 1996.

EUA não dá visto de entrada a aidético e ameaça conferência. Correio de Notícias, Curitiba, 2 jun. 1991. Caderno A, p. 7.

FUNDAÇÃO BIBLIOTECA NACIONAL (Brasil). Biblioteca Nacional Digital. Rio de Janeiro, c2020. Disponível em: http://bndigital.bn.gov.brl. Acesso em: 1 set. 2020.

GALVÃO, Jane. AIDS no Brasil: a agenda de construção de uma epidemia. Rio de Janeiro: ABIA; São Paulo: Editora 34, 2000.

GOFFMAN, Erving. Estigma: notas sobre a manipulação da identidade deteriorada. Tradução de Márcia Bandeira de Mello Leite Nunes. Rio de Janeiro: LTC, 1975.

HERZLICH, Claudine; PIERRET, Janine. Uma doença no espaço público: a AIDS em seis jornais franceses.

Physis - Revista de Saúde Coletiva, Rio de Janeiro, v. 15, supl., p. 71-101, 2005. DOI: https://doi. org/10.1590/S0103-73312005000300005. Disponível em: https://www.scielo.br/scielo.php?script=sci arttext\&pid=S0103-73312005000300005\&lng=pt\&tlng=pt. Acesso em: 1 set. 2020.

JUIZ fecha creche. Correio de Notícias, Curitiba, 26 fev. 1988. Caderno A, p. 6.

MARQUES, Maria Cristina da Costa. A história de uma epidemia moderna: a emergência política da AIDS/ HIV no Brasil. São Carlos: Rima, 2003.

MARQUES, Maria Cristina da Costa. Saúde e poder: a emergência política da Aids/HIV no Brasil. História, Ciências, Saúde-Manguinhos, Rio de Janeiro, v. 9, supl., p. 41-65, 2002. DOI: https://doi.org/10.1590/ S0104-59702002000400003. Disponível em: https://www.scielo.br/scielo.php?script=sci arttext\&pid=S010459702002000400003\&lng=pt\&tlng=pt. Acesso em: 1 set. 2020.

MASSARANI, Luísa; ROCHA, Mariana. Ciência e mídia como campo de estudo: uma análise da produção científica brasileira. Intercom: Revista Brasileira de Ciências da Comunicação, São Paulo, v. 41, n. 3, p. 33-39, set./dez. 2018. DOI: http://dx.doi.org/10.1590/1809-5844201832. Disponível em: https://www.scielo.br/ scielo.php?script=sci_arttext\&pid=S1809-58442018000300033\&tlng=pt. Acesso em: 1 set. 2020.

MOSCOVICI, Serge. A psicanálise, sua imagem e seu público. Tradução de Sonia Fuhrmann. Petrópolis: Vozes, 2012a.

MOSCOVICl, Serge. Representações sociais: investigações em psicologia social. Tradução de Pedrinho A. Guareschi. 9. ed. Petrópolis: Vozes, 2012b.

NASCIMENTO, Dilene Raimundo do; CARVALHO, Diana Maul de (org.). Uma história brasileira das doenças. Brasília, DF: Paralelo 15, 2004. v. 1.

NASCIMENTO, Dilene Raimundo do. As pestes do século XX: tuberculose e Aids no Brasil, uma história comparada. Rio de Janeiro: Editora Fiocruz, 2005. 
PARKER, Richard; AGGLETON, Peter. Estigma, discriminação e AIDS. Tradução de Cláudia Pinheiro. Rio de Janeiro: ABIA, 2001. Disponível em: http://www.abiaids.org.br/ img/media/colecao\%20cidadania\%20direito. pdf. Acesso em: 31 ago. 2020.

PONTES, Felipe Simão; SILVA, Gislene. Mídia noticiosa como material de pesquisa: recursos para o estudo de produtos jornalísticos. In: BOURGUIGNON, Jussara Ayres; OLIVEIRA JUNIOR, Constantino Ribeiro de (org.). Pesquisa em ciências sociais: interfaces, debates e metodologias. Ponta Grossa: Todapalavra, 2012. p. 49-77.

PRECONCEITO, o maior obstáculo na luta dos médicos contra a Aids. Correio de Notícias, Curitiba, 8 mar. 1987. Caderno A, p. 8.

RAMOS, Lissandra Queiroga. Da cara da morte para a cara viva da AIDS: a transição expressa nas campanhas do Dia Mundial de Luta contra a AIDS (1989-2014). 2016. 154 f. Dissertação (Mestrado em História das Ciências e da Saúde) - Casa de Oswaldo Cruz, Fundação Oswaldo Cruz, Rio de Janeiro, 2016. Disponível em: https://www.arca.fiocruz.br/handle/icict/20452. Acesso em: 1 set. 2020.

ROSENBERG, Charles E. Disease in history: frames and framers. The Milbank Quarterly, Nova lorque, v. 67 , supl. 1, p. 1-15, 1989. Disponível em: https://www.milbank.org/quarterly/articles/disease-in-history-frames-andframers/. Acesso em: 1 set. 2020.

ROSENBERG, Charles E.; GOLDEN, Janet Lynne (ed.). Framing disease: studies in cultural history. New Brunswick, New Jersey: Rutgers University Press, 1997.

SCHNEIDER, Eduardo. Sarney quase vira aidético. Correio de Notícias, Curitiba, 25 ago. 1989. Caderno A, p. 4.

SEM informação oficial, a Saúde ignora preso com Aids. Correio de Notícias, Curitiba, 10 nov. 1987. Caderno A, p. 7.

SETEMY, Adriana Cristina Lopes. Vigilantes da moral e dos bons costumes: condições sociais e culturais para a estruturação política da censura durante a ditadura militar. Topoi, Rio de Janeiro, v. 19, n. 37, p. 171-191, jan./abr. 2018. DOI: https://doi.org/10.1590/2237-101x01903708. Disponível em: https://www.scielo.br/scielo. php?script=sci_arttext\&pid=S2237-101X2018000100171\&lng=pt\&tlng=pt. Acesso em: 1 set. 2020.

SCHULMANN, Cila. Ausência. Correio de Notícias, Curitiba, 4 nov. 1992. Caderno A, p. 12.

SONTAG, Susan. Doença como metáfora/AIDS e suas metáforas. Tradução de Paulo Henriques Britto e Rubens Figueiredo. São Paulo: Companhia das Letras, 2007.

ZICMAN, Renée Barata. História através da imprensa: algumas considerações metodológicas. Projeto História, São Paulo, v. 4, p. 89-102, jul. 1985. Disponível em: https://revistas.pucsp.br/revph/article/ download/12410/8995. Acesso em: 1 set. 2020.

ZIMMERMANN, Simone. Número de aidéticos em Curitiba aumenta e é igual ao do Japão. Correio de Notícias, Curitiba, 21 mar. 1992. Caderno C, p. 1. 